\title{
Everyone a Photographer: The Rise of Amateur Photography in the Netherlands 1880-1940
}

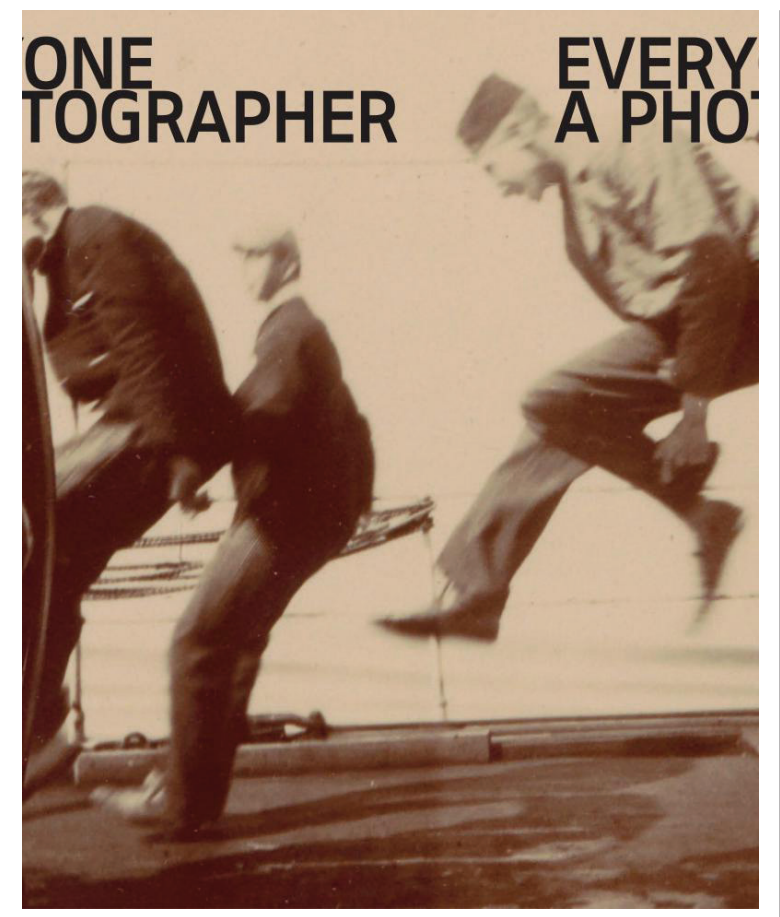

\section{Mattie Boom}

Everyone a Photographer: The Rise of Amateur Photography in the Netherlands 1880-1940

Rijksmuseum/naioro publishers, 2019, 250 pp., € 39,95, ISBN 978-94-6208-477-3

Met het rijkelijk geillustreerde Everyone a Photographer zet Mattie Boom, conservator fotografie aan het Rijksmuseum, een relatief onderbelicht onderwerp in de Nederlandse kunst- en mediageschiedenis vol in de schijnwerpers: de vroege amateurfotografie. De vermaarde grafisch ontwerper Irma Boom is verantwoordelijk voor de uitzonderlijke vormgeving van deze handelseditie, een Engelstalige bewerking van het aan de Erasmus Universiteit Rotterdam verdedigde proefschrift Kodak in Amsterdam: De opkomst van de amateurfotografie in Nederland 1880-1910. De vormgeving van het boek staat bovendien volledig in dienst van de inhoud die grotendeels overeenkomt met het eerder verschenen promotieonderzoek uit 2017 .

Zoals in de dissertatie maakt Boom vooral gebruik van de Franse socioloog Pierre Bourdieu voor haar theoretische raamwerk. Aan de hand van zijn werk over fotografie en concepten als 'habitus', 'veld' en 'cultureel kapitaal' schetst Boom een analytisch kader waarmee zij de sociale dynamiek en het culturele belang van de vroege amateurfotografie scherp kan stellen. Gezien de reeds langdurige invloed van Bourdieu op de kunsten cultuursociologie, maar ook binnen de geschiedbeoefening, is haar benaderingswijze niet bijzonder vernieuwend te noemen. Desondanks weet Boom voldoende te motiveren waarom diens werk een vruchtbaar uitgangspunt blijft om de veelzijdigheid van de vroege jaren van de amateurfotografie te begrijpen. Zo stelt zij terecht in de inleiding dat alle 'ingredients and elements' (p. 27) van Bourdieus model in die periode terug te vinden zijn.

Anders dan in het proefschrift lijkt er, gezien de ondertitel van het boek, een aantal decennia aan de periodisering van de vroege amateurfotografie toegevoegd te zijn. Waar eerder I9I0 het eindpunt markeerde, wordt deze in de handelseditie op I940 gezet. Dit is een opmerkelijke keuze en roept een aantal vragen op. Heeft deze verschuiving te maken 
met nieuw ontsloten bronnenmateriaal? Is deze periodisering ingegeven door meer recent verworven inzichten van Boom of haar vakgenoten? Helaas worden deze vragen niet beantwoord en ontbreekt, net als in het proefschrift, een meer uitvoerige toelichting.

Deze constatering doet echter niets af aan de nauwkeurigheid waarmee Boom de kruisbestuiving beschrijft tussen kunst, educatie, wetenschap en het bedrijfs- en verenigingsleven in de vroege Nederlandse amateurfotografiegeschiedenis. Zij schenkt bovendien veel aandacht aan de pioniers en bespreekt een aantal belangrijke technische experimenten en innovaties binnen de ontwikkeling van de fotografie. Hier toont zich echter wel de beperking van haar conceptuele raamwerk, aangezien een verdere duiding van deze zeer vroege, veelal ongeorganiseerde 'early adaptors' van de fotografie vrijwel achterwege blijft.

De bloei van Nederlandse amateurfotografieclubs komt veel beter tot zijn recht. Het was vooral een bezigheid van de gegoede burgerij, maar was ook populair onder leden van het Nederlandse patriciaat en de aristocratie. Met name hoe amateurfotografie als negentiende en vroegtwintigste-eeuwse vrijetijdsbeoefening intiem verbonden was met de opkomst van de ANWB en de Nederlandse voorliefde voor de fiets, is een tot de verbeelding sprekende vondst. Toch lijkt Boom haar vingers niet te willen branden aan een duiding van de veranderende aard van het dilettantisme, amateurisme en hobbyisme binnen de amateurfotografieclub. Hoewel zij uitgebreid aandacht schenkt aan de vele exposities van kunstzinnige amateurfoto's, wat geruime tijd een obsessie was binnen de fotografieclub, blijft een systematische analyse van de opvattingen rond esthetiek, smaak en vakmanschap onder clubleden achterwege.
Dit gemis wordt grotendeels gecompenseerd door Booms uiteenzetting van het visuele idioom van de amateurfotograaf aan de hand van een zorgvuldige selectie foto's en fotoalbums uit de archieven. De ontsluiting, beschrijving en analyse van de historische foto's is ook veruit de grootste verdienste van haar onderzoek. De in het boek (en de bijbehorende tentoonstelling van het Rijksmuseum) opgenomen foto's zijn bovendien van zeer hoge kwaliteit en erg aansprekend. Het geselecteerde materiaal getuigt van Booms scherpe oog en vooral haar analyse van de fotoalbums biedt vele mooie inzichten. In het hoofdstuk 'Albums' laat zij namelijk ook de alledaagsheid van de amateurfotografie zien. Daarnaast brengt ze de eerder vaak onzichtbaar gebleven vrouwelijke amateurfotografen, en de veelzijdige albums die zij maakten, nadrukkelijk over het voetlicht.

De meer ongepolijste kiekjes die door deze en andere fotoamateurs gemaakt werden konden vaak op hoongelach rekenen van vele 'serieuze' clubamateurs met meer artistieke aspiraties. Toch herinnert Boom ons eraan dat ook deze alledaagse esthetiek omgekeerd weer als inspiratiebron diende voor allerlei kunstenaars en kunststromingen. Tevens benadrukt zij dat deze vorm van amateurfotografie een waardevol inkijkje geeft in de geschiedenis van het alledaagse leven van een deel van de Nederlandse bevolking. Fotografie is kortom een relevante historische bron die niet over het hoofd gezien mag worden. Met deze observatie bepleit Boom dat de amateurfotografie niet alleen relevant is voor de kunst- en mediageschiedenis, maar ook voor sociaalhistorisch of andersoortig onderzoek.

Uiteraard is er sinds de 'visual turn' al veel meer aandacht voor fotografie en de visuele cultuur in (kunst)historisch onderzoek. 
Desalniettemin blijft het belangrijk dit te onderstrepen, met name vanwege de alomtegenwoordigheid van de amateur in het huidige medialandschap. Dit is waarschijnlijk de reden waarom Boom het boek afsluit met een kort epiloog over de status van de amateur in de eenentwintigste eeuw. Op het eerste gezicht lijkt het een erg grote sprong naar het heden, maar deze keuze stelt Boom in staat om een aantal belangrijke veranderingen omtrent

de status van de amateur kort aan te stippen. Tom Slootweg, Universiteit Utrecht
Het verschil tussen de tijd van de 'homo photographicus' (p. I88) en de huidige 'culture of prosumers' (p. 208) laat zien dat er nog veel te vertellen is over amateurfotografie in het Nederland van de twintigste en eenentwintigste eeuw. Hopelijk kan een eventuele vervolgstudie over deze nu nog onbesproken perioden rekenen op een handelseditie met evenveel gevoel voor detail en smaak. 